\title{
Effects of Aggression on Psychological Adjustment of College Students in District Faisalabad
}

\author{
Bushra Naoreen $^{*}$ \\ Azhar Mumtaz Saadi* \\ Jaffar Ali ${ }^{* * *}$
}

\begin{abstract}
Major objective of the current study was to find out the relationship between aggression and psychological adjustment among college students in district Faisalabad. Ten colleges (male $=5$ and female $=5$ ) were randomly selected from the population as sample. One thousand students (male $=500$ and female $=500$ ) were approached conveniently. Data were collected using two instruments: Adults Psychological Adjustment Survey (APAS) and Aggressive Behavior Scale (ABS). Descriptive statistics and pearson $r$ were used to analyze the data. Findings indicated above average level of aggression and below average level of psychological adjustment among college students and a significantly positive relationship between aggression and psychological adjustment. As the level of aggression increases, it weakens the psychological adjustment. All the sub factors of aggression are significantly correlated with sub factors of psychological adjustment. It is recommended that during admission process, students' aggression and psychological adjustment must be considered in addition to academic qualification.
\end{abstract}

Keywords: aggression, psychological adjustment, behaviour

\footnotetext{
* Assistant Professor, GC University Faisalabad, Pakistan. Email: bnaoreen.gcuf@gmail.com

** Assistant Professor (Edu), Allama Iqbal Open University Islamabad Email: drazhargilani@gmail.com

${ }^{* * *}$ M.Phil (Edu) GC University, Faisalabad.
} 


\section{Introduction}

Aggression is a complex term as other psychological phenomena. Therefore it is not very easy to define it in simple words. Whenever the term aggressive is used to describe a student's behavior, images of physical injury to another automatically come to mind. It is considered an inappropriate behavior that has a serious consequence on both the students and his/her environment.

Aggression is usually observed as being proactive, reactive, overt, covert, physical, verbal, or relational (Werner \& Crick, 2004). Psychologists make a distinction between reactive aggression (affective, hostile, angry, and impulsive), penalizing aggression, and proactive aggression (instrumental aggression). They claimed that it is challenge to differentiate between reactive and proactive aggression because motives are often mixed (Bushman \&Anderson, 2001).

Aggression in children and adolescents is the critical issue for psychologists today. Professionals are faced not only with the direct effect of anger and aggression, but also with the indirect effects that appear in the form of learning difficulties and social adjustment problems (Lochman, 2010). Everyday students face challenges with emotion of annoyance, aggravation and disgrace. Harms with violence are inspired different variables and can be conceptualized. Anger reaction is probable to be premeditated and proscribed as in positive violent behavior (Lochman \& Wells, 2002). Anger and violence often are conceptualized inside a social cognitive structure (Dodge, Laird, Lochman \& Zelli, 2002). External inspirations are irritation and violent behavior of students. Among the relatives, parenting practices, youngster abuse, and marital aggression have all been associated to violent behavior in students.

Psychological adjustment is relevant with life changes, coping skills, personality characteristics and social support. Psychological adjustment is what people understand, communicate and live and find worth in their lives. If a person is psychologically well adjusted, he/she may not be aggressive in many situations and vice versa. Keyes, Shmotkin, and Ryff (2002) considered psychological adjustment, the gratification of an entity's objectives and desires to actualization of aptitudes or way of life.

Psychological outcomes are related to the ability to adequately meet the requirements in the satisfaction of the culture and of the new relationship (Sadaf, 2011; Searle \& Ward, 1990). However, psychological problems are related to the great passion of stressors related to migration, the impact of life changes, depression and negative 
coping styles and satisfaction with life (Kia-Keating, 2007). This study focused on aggressive behavior of the students that affects their lives and also found the level of their adjustment in the social group.

\section{Objectives}

The objectives of this study were to investigate the aggression and psychological adjustment level of college students and to find out the relationship between both of these psychological constructs. To address these objectives, following research questions were formulated.

\section{Research Questions}

i. What is the level of aggression among college students?

ii. What is the level of their psychological adjustment?

iii. What is the relationship between aggression and psychological adjustment among students?

\section{Methodology}

\section{Nature of the Study}

As nature of the study was correlational, survey was conducted to collect the data from respondents.

\section{Sample and Sampling Procedure}

Sample of the study was selected conveniently from 850 respondents from 10 public sector degree colleges in a metropolitan city of Pakistan. They were 475 male (55\%) and 375 female (45\%) students whose age ranged from 16 years to 20 years. Among them $346(41 \%)$ were $1^{\text {st }}$ year students whereas $504(59 \%)$ were those in $2^{\text {nd }}$ year. On average their parents were not highly qualified as only185 $(22 \%)$ their fathers and only $90(11 \%)$ of their mothers were graduates.

\section{Instruments of the Study}

Data were collected with the help of two instruments, Aggressive Behavior Scale (ABS) and Adults Psychological Adjustment Survey (APAS). 
Aggressive Behavior Scale (ABS) is used to measure the level of aggression among students. It was developed by Buss and Perry in 1992 and was adapted and translated into Urdu by Iftikhar and Malik in 2017. It consisted of 29 statements on five point likert type scale. It comprised four sub factors i.e. hostility, physical aggression, verbal aggression and anger. Reliability of the ABS is found to be 0.78 .

Adult Psychological Adjustment Questionnaire (APAS) is used to measure the general psychological adjustment of a person. It was developed by Rohner, Ronald P in 2005 and was adapted and translated into Urdu by Fauzia Naz and Rukhsana Kausarin 2012. This questionnaire consists of 63 statements on four points scale. It comprises seven subscalesi.e., hostility/aggression, addiction, negative self-esteem, negative self-adequacy, emotional unresponsiveness, emotional instability and negative worldview. The APAS, including all sub scales, is negative in nature i.e. the higher the score one gets on it, the lower the adjustment level he possesses. In this study, reliability of the APAQ was 0.83 .

\section{Data Analysis}

The data were analyzed by using the SPSS. Descriptive statistics were used to address first two research questions when Pearson $r$ was used to find out the relationship between aggressive behavior and psychological adjustment among college students.

Table 1

Descriptive Statistics for Sub Factor of ABS

\begin{tabular}{llll}
\hline Sub factors & Mean & Std. Deviation \\
\hline Hostility & 2.98 & 0.75 & \\
Physical aggression & 2.89 & 0.64 & \\
Verbal aggression & 2.80 & 0.88 & \\
Over all aggression & 2.80 & 0.57 & $N=850$ \\
Anger & 2.51 & 0.90 &
\end{tabular}

Table 1 addresses first research question which is related to measurement of college students' aggression level. The table is arranged in descending order with reference to their mean score on sub factors of 
ABS and overall aggressive behavior. Their mean score could range from one to five. The more the score one gets, the more the aggressive behaviour one holds. The participants highest mean score $(\mathrm{M}=2.98)$ on hostility shows their extreme resentment whereas their least mean score $(M=2.51)$ on anger shows that they retain an average level of wrath. Mean score on rest of the sub scales ranges between two aforementioned values. A mean score higher than the middle value $(\mathrm{M}=2.50)$ on $\mathrm{ABS}$ and its sub factors shows that college students' aggression level is somewhat higher than average.

Table 2

Descriptive Statistics for Sub Factor of APAQ

\begin{tabular}{llll}
\hline Sub factors & $M$ & $S D$ \\
\hline Dependency & 2.65 & 0.47. \\
Emotional Instability & 2.6 & 0.43 \\
Emotional Unresponsiveness & 2.38 & 0.4 & \\
Over all Psychological Adjustment & 2.34 & 0.3 & \\
Negative Self-Esteem & 2.26 & 0.45 \\
Hostility Aggression & 2.21 & 0.6 & $N=850$ \\
Negative Self Adequacy & 2.18 & 0.45 & 0.57 \\
Negative World View & 2.1 & &
\end{tabular}

Table 2 addresses second research question which is related to measurement of college students' psychological adjustment level. The table is arranged in descending order with reference to their mean score on sub factors of APAQ and overall psychological adjustment. Their mean score could range from one to four. It is a negative construct. Therefore, the more the score on gets, the lower the adjustment level on owns. The participants highest mean score $(\mathrm{M}=2.65)$ on dependency shows they are extremely dependent on others for their psychological adjustment whereas their least mean score $(\mathrm{M}=2.1)$ on negative world view shows that they are average level of negative world viewer. Mean score on rest of the sub scales ranges between two aforementioned values. A mean score higher than the middle value $(\mathrm{M}=2.00)$ on APAQ and its sub factors shows that college students lack adequate skills which are required for psychological adjustment. 
Table 3

Correlation among Sub Scales of ABS and Overall APAS

\begin{tabular}{ll}
\hline Sub Scales of ABS & Overall psychological adjustment (APAS) \\
\hline Physical aggr. & $0.11^{* *}$ \\
Verbal aggr. & 0.04 \\
Anger & $0.34^{* *}$ \\
Hostility & $0.17^{* *}$ \\
Overall Aggressive Behavior & $0.24^{* *}$ \\
\hline
\end{tabular}

**Correlation is significant at the 0.01 level (2-tailed).

Table 3 shows a significantly positive correlation between sub scales of ABS and overall APAS score. Overall, this relationship is not very strong $(r=0.24)$. It implies that the higher the aggression level, the weaker the psychological adjustment level is. The highest correlation is found to be in between anger and overall psychological adjustment $(r=0.34)$ which confirms that one who continues to be angry most of the times tends more to be weak in adopting strategies for psychological adjustment.

\section{Discussion}

By reviewing the literature it was found that aggressive behavior is shown in adolescence (Ryan, 2001) But it has not significant difference among different age groups, gender, their qualification and the qualification of their parents. If the difference exists it is only a slight difference that cannot be a source for major decisions. Many research studies support the findings of this research as Steinberg, Reyome, and Bjornsen (2001) found that aggressive behavior exists in adolescence at different occasions as they have desire to be recognized as popular and powerful among others but it has no relationship with their age and qualification.

Some other studies also support the results of current study as Crain, Finch, \& Foster. (2005) and Juvonen (2002) indicated significantly positive correlation between aggressive behavior and psychological adjustment. Current study shows the relationship but overall, this relationship is not very strong. It implies that the higher the aggression level, the weaker the psychological adjustment level is. The highest 
correlation is found to be in between anger and overall psychological adjustment which confirms that one who continues to be angry most of the times tends more to be weak in adopting strategies for psychological adjustment. Steinberg; Reyome; Bjornsen, and Christopher (2001) also indicated the same findings. They also discussed that the children who suffer loneliness in society they actually experience aggressive behavior. They need a group of friends who appreciate and admire them. If they belong to joint family system the level of aggressiveness is low as compared to separate family systems (Graham \& Juvonen, 2002). This study also found that adolescent ratings of paternal psychological control were positively related to self-reported relational aggression. A study conducted by Little, et al. showed that the higher the level of adjustment of the student, the lower the level of aggression (Little, Brauner, Jones, Nock, \& Hawley, 2003). Findings of this study also correspond with the findings of current study.

Same findings were discussed in another study as Markoe (2003) found that there is a significant relationship between the level of psychological adjustment and the level of aggression of adolescents. Those adolescents who are less aggressive are more adjusted in the society. These findings also correspond with the findings of current study and the study conducted by Klomek, Marrocco, Kleinman, Schonfeld, \& Gould (2007); GülerMurray-Close, Ostrov, Nelson, Crick and Coccaro (2009). It is concluded that as the level of aggression increases, the level of psychological adjustment decreases. Those adolescents who are more adjusted in the society may be less aggressive in their behavior and vice versa.

\section{Recommendations}

This study was carried out only on collegiate and major section of society was overlooked, such as nonstudent people, employed man and women. So it is recommended to be careful while generalizing the result upon other sectors of population.

To generalize the results with high degree of reliability, it is suggested to replicate the study with residence of different cities. 
Parental involvement is necessary to adjust children psychologically in the society.

Educators are suggested to adopt strategies for psychological adjustment of adolescents.

Institutional policies and measures should be planned for emotional and psychological stability of the student. 


\section{References}

Bushman, B. J., \&Anderson, C. A. (2001). Is it time to pull the plug on the hostile versus instrumental aggression dichotomy? Psychol. Rev. 108, 273-279.

Crain, M.M., Finch, C.L., \& Foster, S. L. (2005). The relevance of the social information processing model for understanding relational aggression in girls. Merrill-Palmer Quarterly, 51, 213-242.

Dodge, K. A., Laird, R., Lochman, J. E., Zelli, A., \& Conduct Problems Prevention Research Group. (2002). Multidimensional latentconstruct analysis of children's social information processing patterns: Correlations with aggressive behavior problems. Psychological Assessment, 14, 60-76

Fauzia., \& Rukhsana. (2012). Substance abuse and aggressive behavior among adolescents 8 (9) Published by Canadian Center of Science and Education.

Graham, S., \& Juvonen, J. (2002). Ethnicity, peer harassment, and adjustment in middle school: An exploratory study. Journal of Early Adolescence, 22, 173-199.

Klomek, A. B., Marrocco, F., Kleinman, M., Schonfeld, I. S., \& Gould, M. S. (2007). Bullying, depression, and suicidality in adolescents. Journal of the American Academy of Child \& Adolescent Psychiatry, 46(1), 40-49.

Keyes, C. L. M., Shmotkin, D., \& Ryff, C. D. (2002). Optimizing wellbeing: The empirical encounter of two traditions. Journal of Personality and Social Psychology, 82(6), 1007-1022.

Kia-Keating, M., \& Ellis, B. H. (2007). Belonging and connection to school in resettlement: Young refugees, school belonging, and psychosocial adjustment. Clinical Child Psychology \& Psychiatry, 12(1), 29-43

Little, T. D., Brauner, J., Jones, S. M., Nock, M. K.,\& Hawley, P. H. (2003). Rethinking aggression: A typological examination of the functions of aggression. Merrill-Palmer Quarterly: Journal of Developmental Psychology, 49(3), 343-369.

Lochman, J. E., \& Wells. (2002a). Distorted perceptions in dyadic interactions of aggressive and nonaggressive boys: Effects of prior 
expectations, context, and boys' age. Development \& Psychopathology, 10, 495-512

Lochman, J. E. (2010). Anger and aggression In D. W. Nangle, D. J. Hansen, C. A. Erdley P. J. Norton, Practitioner's guide to empirically based measures of social skills. pp. 155-166. New York: Springer.

PringerMarkoe, S. (2003). Why do some students displaying disruptive behavior incur suspensions, while others do not? Perceived school climate as a possible buffer. Unpublished Master's thesis, University of California, Los Angeles.

Murray-Close, Diana, Ostrov, Jamie M. Nelson; David, A. C., Nicki R., \& Coccaro, E. F. (2009). Proactive, reactive, and romantic relational aggression in adulthood: Measurement, predictive validity, gender differences, and association with Intermittent Explosive Disorder. Journal of Psychiatric doi:10.1016/j.jpsychires.2009.09.005.

Ryan, A.M. (2001). The peer group as a context for the development of young adolescent motivation and achievement. Child Development, 72(4), 1135-1150.

Rohner, R. P., \& Khaleque, A. (2005). Personality assessment questionnaire (PAQ): test manual.

Steinberg, L. D., Reyome, N. D., \& Bjornsen, C. A. (2001). Study Guide for Use with Adolescence. McGraw-Hill Higher Education.p. 100. ISBN 9780072414615.

Searle, W., \& Ward, C. (1990). The prediction of psychological and socio cultural adjustment during cross-cultural transitions. International Journal of Intercultural Relations, 14, 449-464.

Werner, N. E., \& Crick, N. R. (2004). Maladaptive peer relationships and the development of relational aggression and physical aggression during middle childhood. Social Development, 13, 495-514.

\section{Citation of this Article:}

Naoreen, B., Saadi, A. M., \& Ali, J. (2018). Effects of aggression on psychological adjustment of college students in district Faisalabad. Pakistan Journal of Education, 35(1), 1-10. 